EPJ Web of Conferences 76, 01016 (2014)

DOI: $10.1051 /$ epjconf/20147601016

(C) Owned by the authors, published by EDP Sciences, 2014

\title{
Mathematical modeling of heat transfer in closed two-phase thermosyphon
}

\author{
Atlant Nurpeiis ${ }^{\mathrm{a}}$ \\ Postgraduate, Tomsk Polytechnic University, Lenin Str., 30, 634050 Tomsk, Russia
}

\begin{abstract}
There was conducted a numerical analysis of heat-transfer in close two-phase thermosyphon of cylindrical form in the condition of admission of warmth on a lower lid and taking from the high bound of lid. For description of the researched process was offered the simplified mathematical model, which describes only processes of heat conductivity in system "a corps of thermosyphon - a steam channel - a condensate membrane". This formulated task with boundary conditions was decided by the method of eventual differences using an implicit difference scheme. As a result have got fields of temperatures in thermosyphon for typical thermal loads and methods of working. Was conducted a comparative analysis of fields of temperature in a thermosyphon at different thermal streams on a lower lid. Was studied an Influence of coefficient of heat emission and basic geometrical descriptions on forming of the field of temperature in the crossrunner of thermosyphon.
\end{abstract}

Heat pipes [1,2] and thermosyphons [3, 4] are perspective systems of cooling for different equipments. But for the present - thermosyphons are used rarely. It is related to the lack of general theory of the heat transfer convection processes in such systems, which provides the possibility of their practical elaboration. Mathematical models [5, 6], used for description [4] of processes of convection in a steam channel and membrane of refrigerant in thermosyphons, are difficult. It is expediently to elaborate less difficult (as compared to [5, 6]) models, taking into account the thermal effects of evaporation and condensation of refrigerant, and also heat conductivity.

The aim of this work is a mathematical simulation of temperature fields of closed two-phase thermosyphons.

There was examined a thermosyphon the principle layout of which is shown on Fig. 1. The energy of a heat emission source, which is located near-by the lower lid of thermosyphon, enters in the zone of refrigerant evaporation through the border $\mathrm{z}=\mathrm{z}_{1}$. As a result of intensive vaporization there is a drop in pressure. Steams quickly move to the high bound of a steam channel, the temperature of which below condensation temperature of the material which used as refrigerant. Steam condenses. An appeared liquid under the influence of gravity flows down on vertical walls of steam channel and spreads on surface of lower lid of thermosyphon. Processes of evaporation and condensation continue during the period of heat addition on a low bound and taking from the high bound of lid of thermosyphon. Phase transitions on phase boundary provide heat removal from equipment that gives of warmth. In

\footnotetext{
${ }^{a}$ Corresponding author: Nurpeiis_Atlant@mail.ru
}

This is an Open Access article distributed under the terms of the Creative Commons Attribution License 4.0, which permits unrestricted use, distribution, and reproduction in any medium, provided the original work is properly cited. 


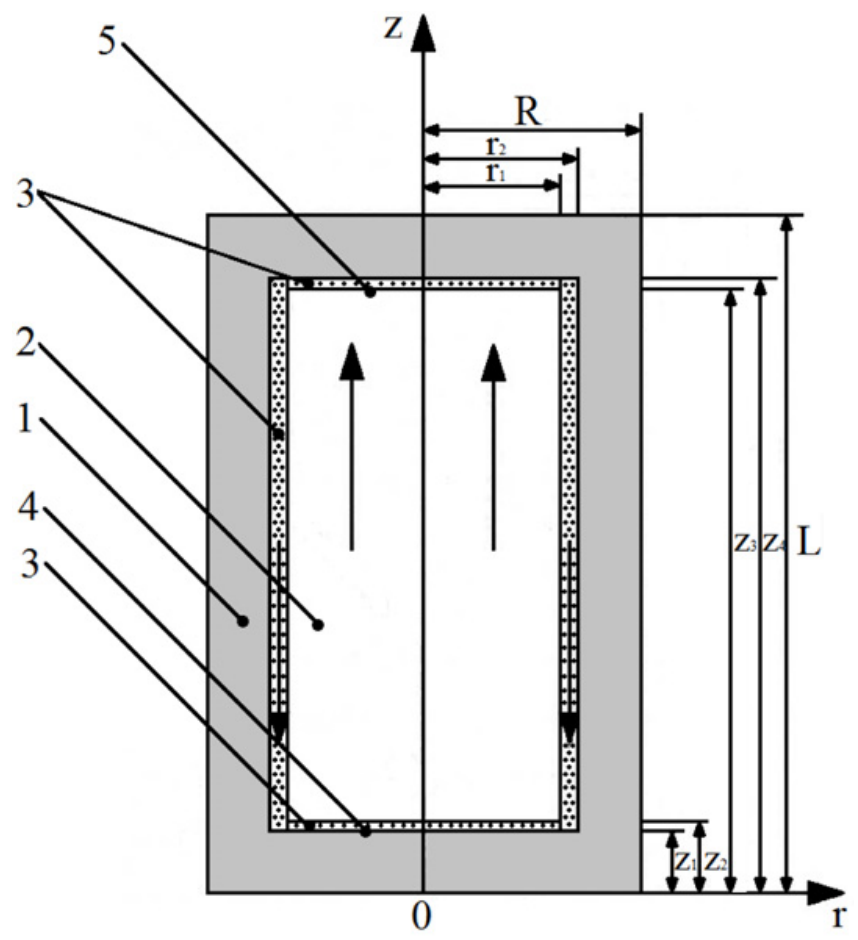

Figure 1. Chart of the closed thermosyphon: 1 - metallic corps; 2 - steam channel; 3 - membrane of liquid; 4 surface of evaporation; 5 - surface of condensation. Vertical pointers show directions of motion of steam and liquid.

majority practically meaningful applications thermosyphons work during the protracted periods of time in stationary modes. Therefore at raising of task of heat transfer, row of assumptions is possible. The followings are basic.

1. Characteristic times of steams motion in the channel of thermosyphon much less than characteristic times of heat conductivity in liquid membrane on lower and overhead lids of thermosyphon, therefore the processes of steam motion in the channel of thermosyphon are not examined.

2. In the stationary operating modes the specifications of a condensate membrane movement process on the side of steam channel do not depend on time, therefore a thickness of the refrigerant membrane can be accepted as permanent at raising of a task.

Formulated assumptions do not give an important limits on raising of a task. Phase transitions on the low and high bounds of a steam channel are fundamental in the complex of processes of heat-mass transfer in thermosyphon. At the permanent intensity of liquid evaporation (and also a steams condensation on overhead lid) condensate will go back into a zone of warmth admission under the action of gravity with speed, which is not depend on speed of its evaporation on the low bound of steam channel. With the growth of vaporization intensity the pressure fall increases in channel (2) (Fig. 1) and the speed of steams uplift to condensation surface also. It is always possible to estimate limit values of condensate membrane movement parameters, in case of reaching which a crisis of "complete boil-off of refrigerant" on lower lid of thermosyphon can be. Pursuant, the simulation within of Navier - Stoks $[5,6]$ or Prandtl's [2] models of steams motion in channel (2) and membrane of condensate (3), cannot 


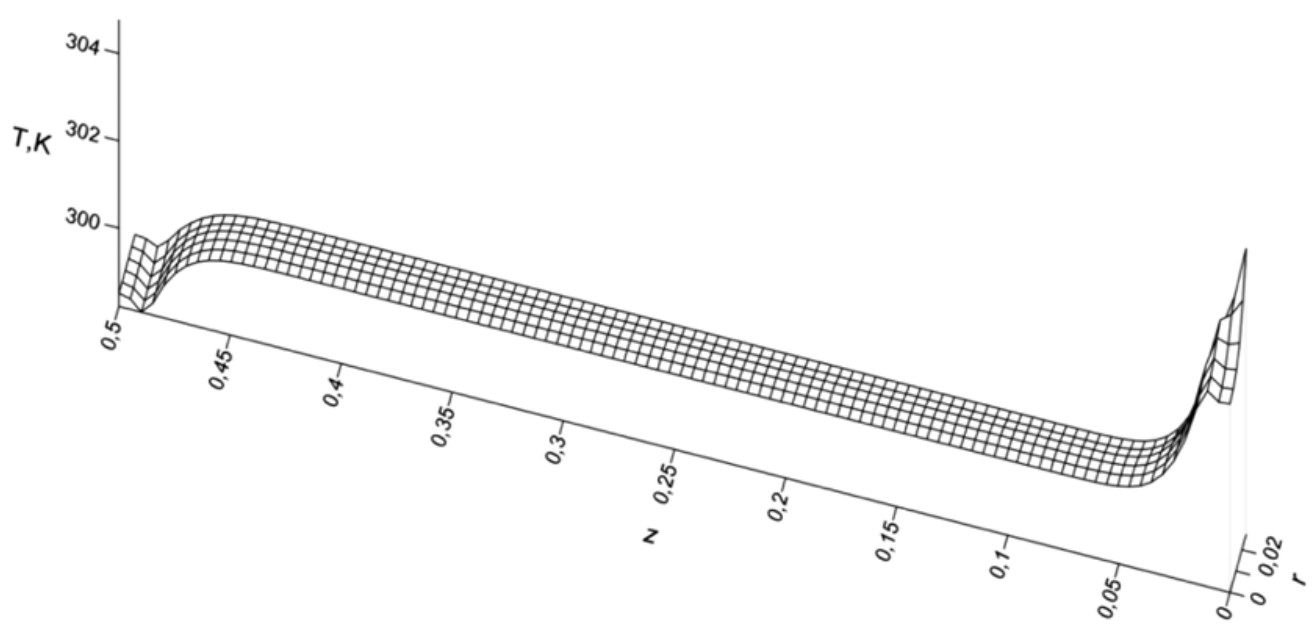

Figure 2. Temperature field of thermosyphon. On Figs. 2, 3 the typical results of numeral design. They illustrates temperature fields of area of decision.

give substantial changes of integral descriptions of heat transfer during thermosyphon's work in several practically meaningful cases.

Meanwhile the decision of complete system of viscid liquid equalization [5, 6] at the description of steam motion in a channel (2) can result the increase of calculations time. Even passing to the model of boundary layer [2] is attended with the protracted calculations in decision of the task of the heat transfer in thermosyphons. Therefore the assumptions chosen while raising of the task creates objective pre-conditions for substantial decline of time expenses at its decision in condition of accounting the basic meaningful factors and processes.

The process of heat transfer in examined thermosyphon (Fig. 1) described by the system of differential equalizations of heat conductivity in partial derivative with proper boundary conditions within accepted physical model.

$$
\begin{gathered}
\frac{\partial T_{1}}{\partial t}=a_{1}\left(\frac{\partial^{2} T_{1}}{\partial r^{2}}+\frac{1}{r} \cdot \frac{\partial T_{1}}{\partial r}+\frac{\partial^{2} T_{1}}{\partial z^{2}}\right) \begin{array}{l}
0<r<r_{1}, \\
r_{2}<r<r_{3},
\end{array} \quad 0<z<z_{3} \\
\frac{\partial T_{2}}{\partial t}=a_{2}\left(\frac{\partial^{2} T_{2}}{\partial r^{2}}+\frac{1}{r} \cdot \frac{\partial T_{2}}{\partial r}+\frac{\partial^{2} T_{2}}{\partial z^{2}}\right) \quad \begin{array}{l}
0<r<r_{1} \\
z_{1}<z<z_{2}
\end{array} \\
\frac{\partial T_{3}}{\partial t}=a_{3}\left(\frac{\partial^{2} T_{3}}{\partial r^{2}}+\frac{1}{r} \cdot \frac{\partial T_{3}}{\partial r}+\frac{\partial^{2} T_{3}}{\partial z^{2}}\right) \quad \begin{array}{l}
r_{1}<r<r_{2} \\
z_{1}<z<z_{2}
\end{array} \\
t=0: T_{1}=T_{0}, T_{2}=T_{0}, T_{3}=T_{0}, \\
r=0,0<z<z_{1}, z_{4}<z<L: \frac{\partial T_{1}}{\partial r}=0, t>0 ; \\
r=0, z_{2}<z<z_{3}: \frac{\partial T_{2}}{\partial r}=0, t>0 ; \\
r=0, z_{1}<z<z_{2}, \quad z_{3}<z<z_{4}: \frac{\partial T_{3}}{\partial r}=0, t>0 ;
\end{gathered}
$$




\section{EPJ Web of Conferences}

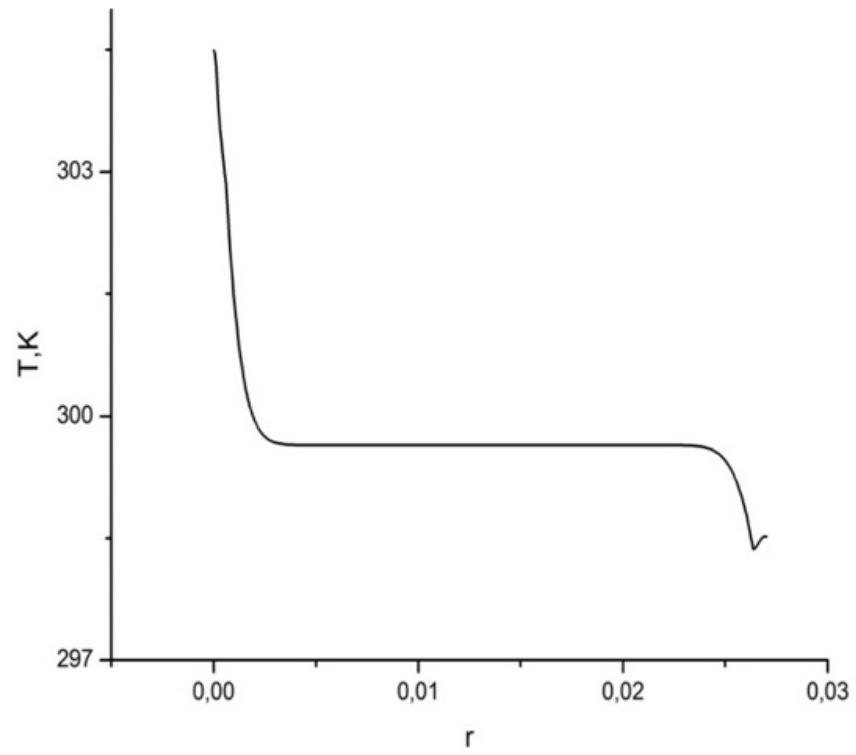

a)

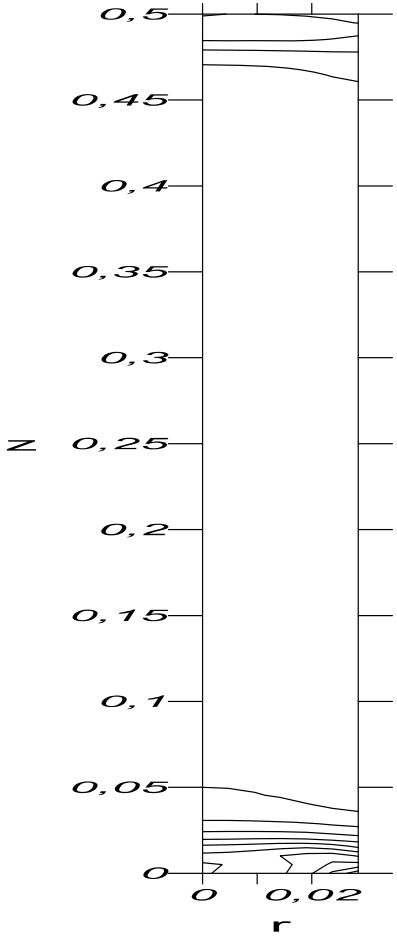

b)

Figure 3. a) Distributing of temperature for $r(z=L / 2)$; b) lines of isotherms of thermosyphon.

$$
\begin{aligned}
& r=r_{3}, 0<z<L: \lambda_{1} \frac{\partial T_{1}}{\partial r}=\alpha\left(T_{e}-T_{1}\right), t>0 \\
& r=r_{1}, z_{2}<z<z_{3}: T_{2}=T_{3},-\lambda_{2} \frac{\partial T_{2}}{\partial r}=-\lambda_{3} \frac{\partial T_{3}}{\partial r}, t>0 \\
& r=r_{2}, z_{1}<z<z_{4}: T_{3}=T_{1},-\lambda_{3} \frac{\partial T_{3}}{\partial r}=-\lambda_{1} \frac{\partial T_{1}}{\partial r}, t>0 \\
& z=0,0<r<r_{3}:-\lambda_{1} \frac{\partial T_{1}}{\partial z}=q, t>0 \\
& z=L, 0<r<r_{3}: \lambda_{1} \frac{\partial T_{1}}{\partial y}=\alpha\left(T_{e}-T_{1}\right), t>0 \\
& z=z_{1}, 0<r<r_{1}: T_{1}=T_{3},-\lambda_{1} \frac{\partial T_{1}}{\partial z}+Q_{u c n} \cdot w_{u c n}=-\lambda_{3} \frac{\partial T_{3}}{\partial z}, t>0 \\
& z=z_{2}, 0<r<r_{1}: T_{3}=T_{2},-\lambda_{3} \frac{\partial T_{3}}{\partial z}=-\lambda_{2} \frac{\partial T_{2}}{\partial z}, t>0
\end{aligned}
$$




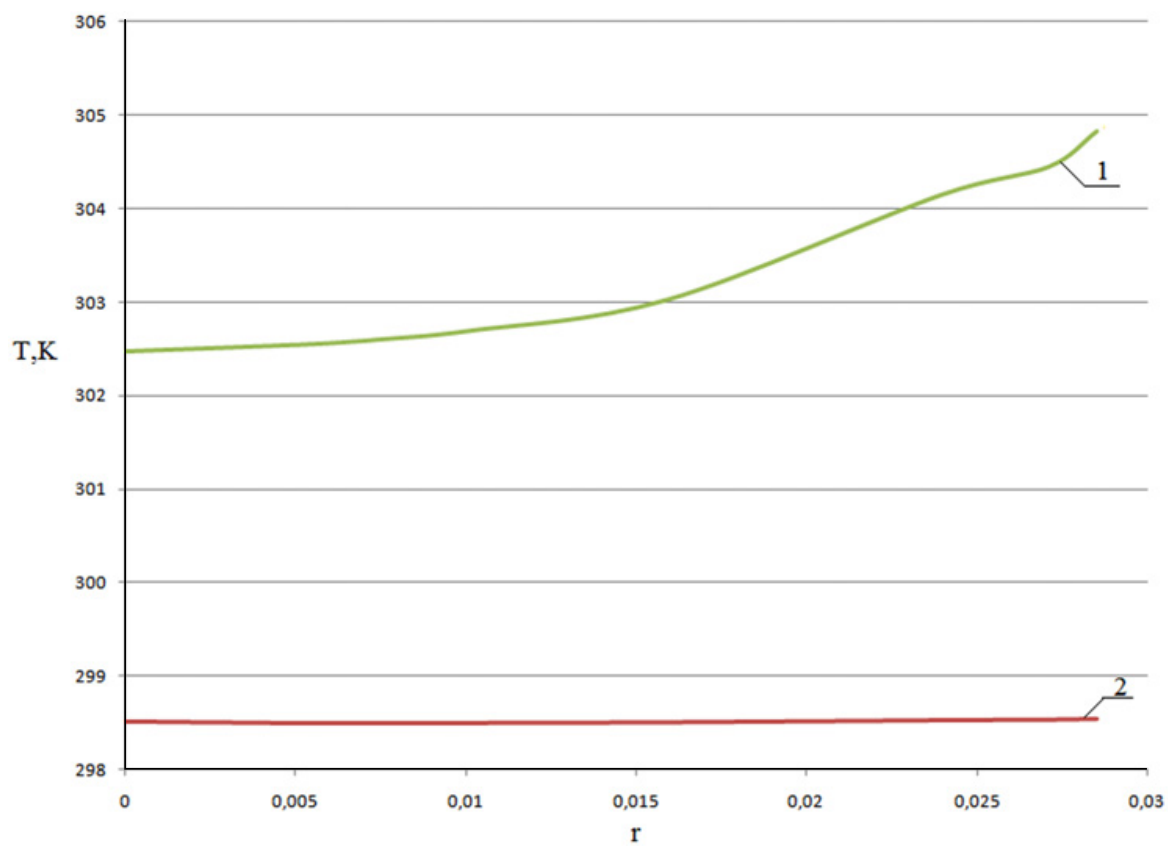

Figure 4. Profile lines of temperatures in sections $z=0$ (1) on a lower lid and $z=0.5$ (2) on an overhead lid. From a Figs. 2-4 evidently, that the gradients of temperatures in the direction of co-ordinate $\mathrm{z}$ do not exceed $12 \mathrm{~K} / \mathrm{m}$. In transversal direction overfalls of temperatures do not exceed $6 \mathrm{~K}$.

$$
\begin{gathered}
w_{u c n}=\frac{A\left(P^{H}-P^{*}\right)}{\sqrt{\frac{2 \pi R T}{M}}} \\
z=z_{3}, 0<r<r_{1}: T_{2}=T_{3},-\lambda_{2} \frac{\partial T_{2}}{\partial z}=-\lambda_{3} \frac{\partial T_{3}}{\partial z}, t>0 ; \\
z=z_{4}, 0<r<r_{2}: T_{3}=T_{1},-\lambda_{3} \frac{\partial T_{3}}{\partial z}-Q_{K O H} \cdot w_{K O H}=-\lambda_{1} \frac{\partial T_{1}}{\partial z}, t>0 ;
\end{gathered}
$$

Here $r, z$ are coordinates of cylindrical system of coordinates; $a$ - coefficient of thermal diffusivity; $q$ - thermal stream; $\lambda$ - coefficient of heat conductivity; $\alpha$ - coefficient of heat exchange; $Q_{u c n}-$ warmth of evaporation; $Q_{K O H}-$ warmth of condensation; $w_{u c n}-$ speed of evaporation; $w_{K O H}-$ speed of condensation; $T_{e}$ - ambient temperature; $P^{H}$ - pressure of the saturated steam; $P^{*}-$ pressure of steams; $A$-coefficient of accommodation; $R$ - universal gas permanent; $M$ - molecular weight.

System of equalizations (1) - (3) with nonlinear border conditions (4) - (17) decided by the method of eventual differences. An iteration algorithm [7, 8] was used. It was developed for decision of more intricate tasks of heat transfer in conditions of attended heat exchange in multiply connected areas. Basic difficulties in decision of border task (1) - (17) consist in intensive heat generation on the surface of condensation of overhead lid of thermosyphon and, accordingly, absorption of warmth on lower lid. For providing the stability and precision of numeral decision by analogy $[7,8]$ a differential grid with steps at times from $10^{-3} \mathrm{~s}$ to $10^{-5} \mathrm{~s}$ was used. At such grid parameters a numeral simulating with thermal streams up to $10^{3} \mathrm{Vt} / \mathrm{m}^{2}$ was possible.

A numerical analysis was conducted for the thermosyphon of cylindrical form with steel walls. As working liquid was examine steam vapor with the proper thermophysical descriptions. The typical 
geometrical sizes of thermosyphon were chosen: a height $-50 \mathrm{sm}$, a radius of steam channel $-25 \mathrm{~mm}$, a thickness of membrane of liquid $-1 \mathrm{~mm}$, a thickness of walls $-2.5 \mathrm{~mm}$.

The developed mathematical model differs from the known balanced models [9, 10], that describes heat-transfer ability of thermosyphons with use of experimental information, by possibility of calculation of temperatures of surface of lower lid in any cross section. The last is important at analysis and estimation of limit thermal loadings on thermosyphons. Malfunctions of work are possible in conditions of overheat and subsequent complete drainage of surface of lower lid. The developed handling to analysis of thermal modes of thermosyphons allows calculating parameters of limit terms their work.

It is also necessary to mark that the formulated mathematical model of heat transfer in thermosyphons can be developed on modes of intensive boiling of liquid refrigerant on surface of boiling of lid of thermosyphon at thickness of membrane a few millimeters. In this case algorithm of numeral decision becomes complicated in connection with growth of intensity of absorption of energy in area of boiling. But, on the other hand, the range of temperatures and thermal streams, arrived at during work of thermosyphon broadens.

\section{References}

[1] Ohashi K., Hayakawa H., Yamada M. Preliminary study on the application of the heat pipe to the passive decay heat removal system of the modular HTR // Prog. Nucl. Energy. (1998) -V. 32. No 3/4. - P. 587-594

[2] Kuznetsov G.V., Sitnikov A.E. Numerical analysis of basic regularities of heat and mass transfer in a high-temperature heat pipe // High Temperature. - (2002) - V. 40. - No 6. - P. 898-904

[3] Безродный М.К., Пиоро И.Л., Костюк Т.О. Процессы переноса в двухфазном термосифонных систеамх. - Киев: Факт, (2005) - 704 с

[4] Kuznetsov G.V., Al-Ani M.A., Sheremet M.A. Numerical analysis of convective heat transfer in a closed two-phase thermosyphon // Journal of Engineering Thermosyphon. - (2011) - V.20. -No 2. - P. 201-210

[5] Kuznetsov G.V., Sheremet M.A. Mathematical modeling of complex heat transfer in a rectangular enclosure // Thermophysics and Aeromechanics. - (2009). - V. 16. - No 1. - P. 119-128

[6] Kuznetsov G.V., Sheremet M.A. New approach to the mathematical modeling of thermal regimes for electronic equipment // Russian Microelectronics. - (2008). - V. 37. - No 2. - P. 131-138

[7] Kuznetsov G.V., Strizhak P.A. The influence of heat transfer conditions at the hot particle-liquid fuel interface on the ignition characteristics // Journal of engineering Thermophysics. - (2009) V. 18. - No 2. - P. 162-167

[8] Kuznetsov G.V., Strizhak P.A. Transient heat and mass transfer at the ignition of vapor and gas mixture by a moving hot particle // International Journal of Heat and Mass Transfer. - (2010) V. 53. - No 5-6. - P. 923-930

[9] Фролов В.П., Шелгинский А.Я. Тепловые трубы в системах теплоснабжения // Энергосбережение. - (2004) - No 6. - С. 58-62

[10] Tsai T.E., Wu H.H., Chang C.C., Chen S.L. Two-phase closed thermosyphon vapor-chamber system for electronic cooling // International Communications in Heat and Mass Transfer. (2010) - V. 37. - No 5. - P. 484-489 